\title{
Infodemic within a Pandemic - The Case of COVID-19 and Urban India
}

\author{
Sukhpreet D Patel ${ }^{1, *}$, Purnendu Nath ${ }^{2}$
}

\section{Sukhpreet D Patel ${ }^{1, *}$, Purnendu Nath ${ }^{2}$ \\ ${ }^{1}$ Nowrosjee Wadia Maternity Hospital, Mumbai, Maharashtra, INDIA. \\ 'London Business School, Regent's Park, London, UK.}

\section{Correspondence}

\section{Dr. Sukhpreet D Patel}

Nowsrosjee Wadia Maternity Hospital, 91 Vallabh Apartments, 87 Bhulabhi Desai Road, Mumbai 400026, Maharashtra, INDIA.

Mobile no: +912223645245

Email: sukhpreetpatel@gmail.com

History

- Submission Date: 18-05-2020

- Revised Date: 16-07-2020

- Accepted Date: 25-08-2020

DOI : 10.5530/ijmedph.2020.3.24

Article Available online

http://www.ijmedph.org/v10/i3

\section{Copyright}

(C) 2020 Phcog.Net. This is an openaccess article distributed under the terms of the Creative Commons Attribution 4.0 International license.

\begin{abstract}
Context: Information related to COVID-19 has been copiously accessible by almost everyone through various modes since its emergence in December 2019 with possible divergence in beliefs about the sources of infection and the actions to take to reduce morbidities and mortality, giving rise to the COVID-19 infodemic. Aim: (i) to report on the variability in the comprehension of COVID-19 related mortality information (ii) to document how varied the sources of information that a population relies on are (iii) to understand the motivation behind implementation of social distancing norms amongst this population (iv) to suggest methods to reduce the burden of an infodemic within a pandemic by creating herd immunity against misinform ants. Settings and Design: An online survey was conducted amongst urban educated individuals on 19 April 2020. Methods and Materials: The survey was conducted using Google forms and sent via WhatsApp chat messages to 949 individuals belonging to various chat groups, of whom 96 replied voluntarily. Results: Even though most (92.71\%) of the participants derived their information from 'trustworthy' sources, there was a large amount of variation in their interpretation of that data. Conclusion: We demonstrated that educated urban professionals have been negatively affected by the infodemic around the COVID-19 pandemic and suggest broad guidelines for future information flow to be better handled through programmes such as "information vaccination" and "modified herd immunity" so that an infodemic is controlled and leads to better outcomes from any epidemic.

Key words: COVID-19, Infodemic, Pandemic, Coronavirus, Herd immunity.

Key Messages: Infodemics have the power to escalate fiercely and to change the course of an outbreak. Hence, the need for prevention protocols in place before their onset.
\end{abstract}

\section{INTRODUCTION}

One of the biggest challenges we are facing during the COVID-19 pandemic is its parallel infodemic. In its situation report on 2 Feb 2020, the World Health Organization (WHO) described an infodemic as 'an overabundance of information - some accurate and some not - that makes it hard for people to find trustworthy sources and reliable guidance when they need it. ${ }^{1}$

Attributing to traditional media coverage and communication by local and international health authorities, information related to COVID-19 is copiously accessible. However, the quality of this information, its interpretation and finally application in terms of human action depends on numerous variables. Besides, a plethora of good quality facts can also be overwhelming to deal with for an already anxious population looking for direction during a pandemic.

The purpose of this paper was to investigate the following by means of a survey of urban educated Indians: (i) to report on the variability in the comprehension of COVID-19 related mortality information (ii) to document how varied the sources of information that a population relies on are (iii) to understand the motivation behind implementation of social distancing norms amongst this population (iv) to suggest methods to reduce the burden of an infodemic within a pandemic by creating herd immunity against misinform ants.

\section{SUBJECTS AND METHODS}

On 19 April 2020, we conducted a survey to understand the perception of COVID-19 statistics available to the population, their sources and its relationship, if any, to the importance of social distancing (Figure 1).

The survey was conducted using Google forms and sent via WhatsApp chat messages to 949 individuals belonging to various chat groups. The population included only urban, educated adults who had access to the internet. Considering that most sources of information are updated once a day, only 96 anonymous participants of the 949 requests who voluntarily responded to the survey within twentyfour hours were included in the study in order to capture a 'representative snapshot in time'. In order to avoid invoking subtle cognitive biases from fear and panic, care was taken to avoid the use of the word 
'mortality' and, instead, optimistic indirect questioning regarding the possibility of 'surviving' COVID-19 was used.

\section{RESULTS}

Findings of our survey are summarised in Table 1.

A. Demography: The respondents of the survey were mainly female $(81.3 \%)$ with a median age of 45 years. The large proportion

Table 1: Results of the Survey.

\begin{tabular}{|c|c|}
\hline Category & Result \\
\hline \multicolumn{2}{|l|}{ Age in years } \\
\hline Median & 45 \\
\hline Range & $18-65$ \\
\hline \multicolumn{2}{|l|}{ Gender } \\
\hline Males & $18.70 \%$ \\
\hline Females & $81.30 \%$ \\
\hline \multicolumn{2}{|l|}{ Days since lock-down } \\
\hline Median & 28 \\
\hline Range & $1-30$ \\
\hline \multicolumn{2}{|l|}{ Number of visits outside the house } \\
\hline Median & 4 \\
\hline Range & $0-30$ \\
\hline \multicolumn{2}{|l|}{ Probability of surviving Novel Coronavirus infection } \\
\hline 95 to $99 \%$ & 21 \\
\hline 90 to $94 \%$ & 24 \\
\hline 85 to $89 \%$ & 17 \\
\hline 80 to $84 \%$ & 6 \\
\hline 75 to $79 \%$ & 20 \\
\hline 50 to $55 \%$ & 2 \\
\hline Other & 5 \\
\hline Unaware & 1 \\
\hline \multicolumn{2}{|l|}{ Source of information } \\
\hline e-version of your favourite newspaper & 12 \\
\hline Websites of official bodies such as the local government & 13 \\
\hline International bodies such as the $\mathrm{WHO}$ and $\mathrm{CDC}$ & 26 \\
\hline WhatsApp forwards from friends and family & 2 \\
\hline News feeds on your phone & 9 \\
\hline Television news channel & 26 \\
\hline My doctor / doctor friends & 3 \\
\hline Other & 5 \\
\hline \multicolumn{2}{|l|}{ Motivation to stay indoors } \\
\hline Not obeying the lock-down is a punishable offence & 0 \\
\hline $\begin{array}{l}\text { I am aware that suffering from Covid- } 19 \text { can be fatal and I } \\
\text { wish to keep myself and my family safe }\end{array}$ & 79 \\
\hline I want to reduce the burden on the medical community & 13 \\
\hline Other & 4 \\
\hline
\end{tabular}

of females in the sample can be explained by the composition of the database of contacts used in this survey.

B. Lockdown Discipline: Since the participants were not restricted to one region, they were questioned about the date on which lockdown was implemented for them. The average number of days of lockdown was 29.1 (median $=28$ days), with the average number of visits outside the house per individual during the lockdown period amounting to 5.18 (median $=4$, range 0 to 30 ).

C. Interpretation and Source of Mortality Data by the Respondents: In order to avoid the effects of pessimism during these trying times, the participants were questioned about the probability of an individual of 'surviving' a SARS-Cov2 infection instead of 'dying' from it. We then subtracted the ranges from 100 to understand their perception of the probability of death from a SARS-Cov2 infection. For example, the probability of survival of 95 to $99 \%$ was interpreted as that of death of 1 to $5 \%$. Figure 2 demonstrates the variability in the interpretation of the fatality data by the participants. A small proportion of respondents $(5.21 \%)$ were of the opinion that survival post-infection depended on factors such as age and/or immunity of the individual and one respondent was not aware of statistics relating to COVID-19 survival.

On enquiring about the source of information, $92.71 \%$ of the participants relied on information from sources that were trustworthy (excluding Whatsapp forwards from friends and family and other).

\section{Table 2: Information Released by the Media}

\begin{tabular}{|c|c|c|}
\hline Date & Information conveyed & Source \\
\hline $\begin{array}{l}3 \text { March } \\
2020\end{array}$ & $\begin{array}{c}\text { Globally, about } 3.4 \% \text { of reported COVID-19 } \\
\text { cases have died. By comparison, seasonal } \\
\text { flu generally kills far fewer than } 1 \% \text { of those } \\
\text { infected. }\end{array}$ & $\mathrm{WHO}^{2}$ \\
\hline 30 & The research, published in the medical journal & $\mathrm{CNN}^{3}$ \\
\hline $\begin{array}{c}\text { March } \\
2020\end{array}$ & $\begin{array}{c}\text { The Lancet Infectious Diseases, estimated that } \\
\text { about } 0.66 \% \text { of those infected with the virus } \\
\text { will die. }\end{array}$ & \\
\hline $\begin{array}{l}2 \text { April } \\
2020\end{array}$ & $\begin{array}{c}\text { Estimates that authorities had made so far put } \\
\text { the death rate for confirmed cases between } \\
2 \% \text { and } 8 \% \text { and the death rate for overall cases } \\
\text { between } 0.2 \% \text { and } 1.6 \% \text {. }\end{array}$ & $\begin{array}{l}\text { Economic } \\
\text { Times }^{4}\end{array}$ \\
\hline $\begin{array}{l}10 \text { April } \\
2020\end{array}$ & $\begin{array}{l}\text { India so far has reported } 6,761 \text { confirmed } \\
\text { cases of coronavirus with a death toll of } 206 \text {, } \\
\text { making it } 3.04 \text { percent death rate ---percentage } \\
\text { of deaths with respect to the total number of } \\
\text { confirmed cases. }\end{array}$ & $\begin{array}{l}\text { Economic } \\
\text { TImes }^{5}\end{array}$ \\
\hline $\begin{array}{l}10 \text { April } \\
2020\end{array}$ & $\begin{array}{c}\text { India's COVID-19 death rate of about } 3.1 \% \text { is } \\
\text { much lower than } 12.72 \% \text { of Italy, } 12 \% \text { of UK, } \\
9.73 \% \text { of Spain, } 3.4 \% \text { of the US and } 5.98 \% \\
\text { global death rate }\end{array}$ & Livemint $^{6}$ \\
\hline $\begin{array}{l}16 \text { April } \\
2020\end{array}$ & $\begin{array}{l}\text { On Tuesday, with } 12 \text { new corona deaths } \\
\text { totalling to } 160 \text {, the state achieved a mortality } \\
\text { rate of } 6.84 \text { per cent. In comparison, with } 5,702 \\
\text { new deaths, the total global deaths stood at } \\
111,652 \text { or mortality rate stood at } 6.29 \text { per cent. } \\
\text { Against this, the Indian average mortality rate } \\
\text { was only } 3.27 \text { per cent with } 32 \text { new deaths and } \\
\text { total } 338 \text { casualties. }\end{array}$ & $\begin{array}{l}\text { Times of } \\
\text { India }^{7}\end{array}$ \\
\hline $\begin{array}{l}18 \text { April } \\
2020\end{array}$ & $\begin{array}{l}\text { Percentage of deaths per closed case globally } \\
\qquad-21.22 \%\end{array}$ & Worldometer $^{8}$ \\
\hline
\end{tabular}


D. Motivation to Stay Indoors during the Lockdown: The main factor motivating participants of this survey to stay at home during the lockdown was to protect themselves and their families from the fatality of COVID-19 (82.29\%). Whereas the intention for a smaller proportion (13.54\%) was to reduce the burden on the medical community, none of the participants chose to stay indoors with the fear of being penalised by authorities.

The survey was conducted on a segment of the population that one might expect, ex-ante, to be well-informed. When extending the results of our findings to a wider population, especially lower socio-economic groups, the deleterious effects of an infodemic within an epidemic will be more pronounced.

\section{DISCUSSION}

Going back to the WHO's description of an infodemic: 'an overabundance of information - some accurate and some not - that makes it hard for people to find trustworthy sources and reliable guidance when they need it. ${ }^{\prime}$

The responses to our survey are evidence of this infodemic within this pandemic. They clearly demonstrate how variedly informed an urban, educated group of individuals is regarding COVID-19 survival and mortality, despite the vast majority $(92.71 \%)$ sourcing their information from 'trustworthy' origins. Table 2 enlists a few examples of COVID-19 mortality related information available to the public from various sources, further explaining the reason for our results. As demonstrated in Table 2, the use of dissimilar parameters to express COVID-19 mortality and the use of unscientific terms such as 'death rate' by traditional media are potential sources for inconsistent interpretations of numerical information by the community. In addition, the conventional Case Fatality Rate (CFR), usually used to quantify the severity of a disease, has

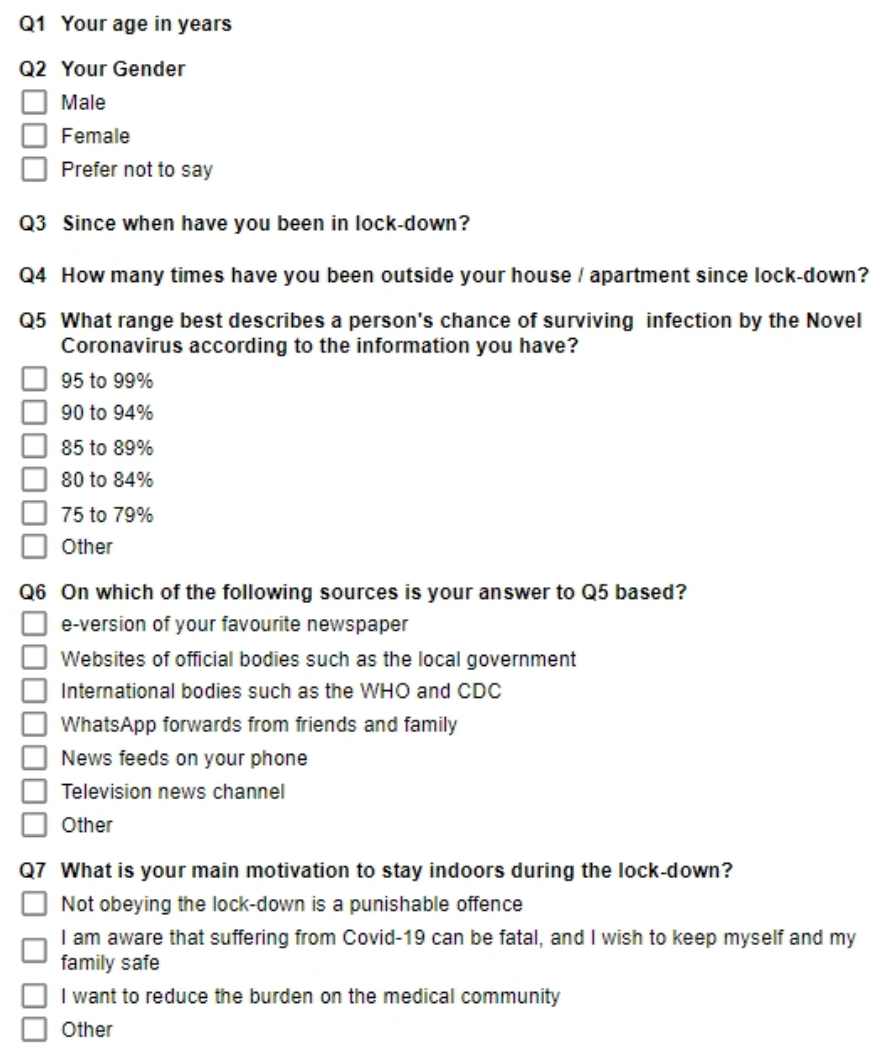

Figure 1: Survey Format. been reported by various sources but has questionable application during an ongoing pandemic. ${ }^{8,9}$ On the other hand, figures on the website of one of the most popular COVID-19 data providers', Worldometer, depict COVID-19 mortality as a percentage of closed cases as opposed to the total infected cases used in CFR, giving rise to a much higher figure than the CFR (21.22\% versus $6.89 \%$ on 18 April 2020), planting one more seed of confusion for the layperson. ${ }^{10}$ The need and framework for a MidEpidemic Case Fatality Rate (ME-CFR) have been proposed. ${ }^{9}$

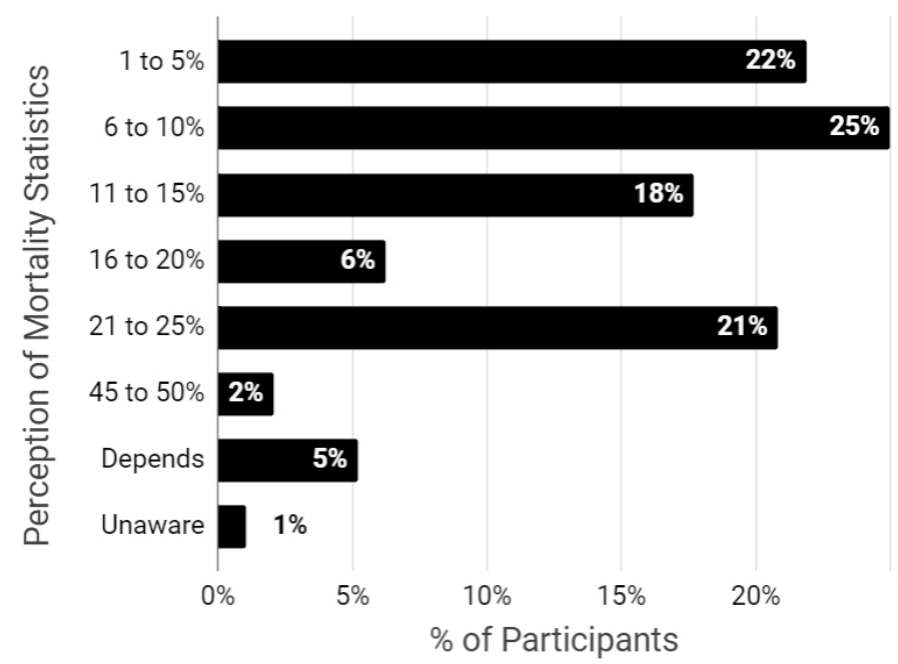

Figure 2: Percentage of Participants vs. Perception of Mortality Statistics.

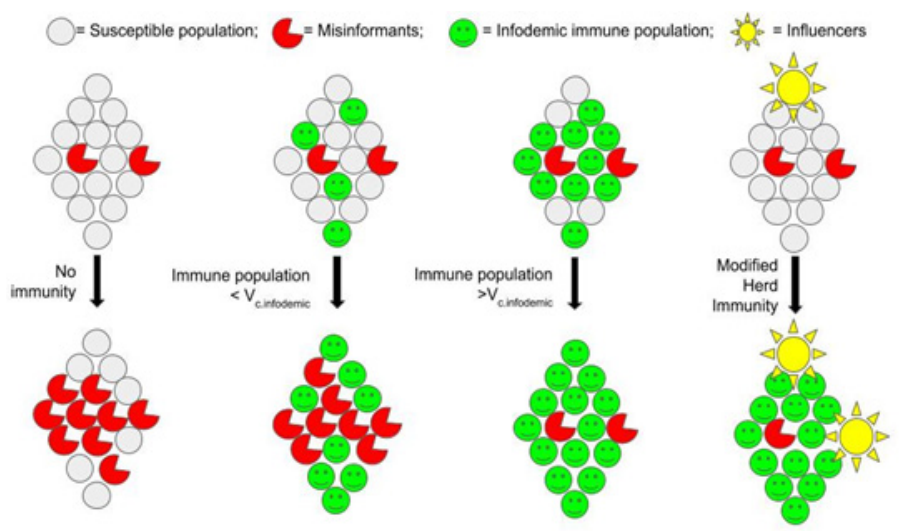

Figure 3: Herd Immunity for an Infodemic.

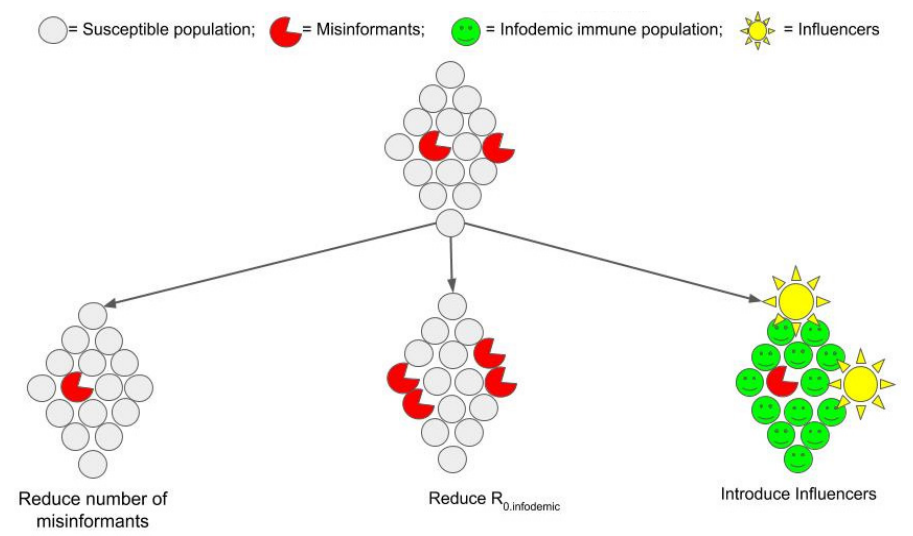

Figure 4: Methods of Reducing $V_{\text {c.infodemic. }}$ 
A similar analysis of website contents for COVID-19 not only revealed significant differences between recommendations from official public health organisations versus digital media, but also detected country-wise differences in simple instructions for hand-washing, covering the mouth while coughing and staying at home if unwell. ${ }^{11}$

Social distancing, the new mantra of survival, has had different consequences for people worldwide - from stock market volatility to the loss of income for daily wage workers - its impact has spared nobody. However, its implementation requires community participation. Whereas our survey revealed that the motivation to stay indoors for most participants was the awareness of the fatality of COVID-19, this was an informed urban population, that did not depend on daily wages. In contrast, thousands of labourers gathered to board homeward bound trains on 14 April 2020, at the Bandra Terminus in Mumbai, requiring intervention by the authorities. It is for episodes such as these that risk communication, focused on risk perception of the community is core to cooperation. The ultimate prevention measure for COVID-19 is selfcare, which requires clear instructions to the community through trustbased communication of risk information. ${ }^{12}$

Our experience with the influenza pandemic has made us familiar with the importance of risk communication. In theory! Frameworks for communication preparedness, implementation and recommendations for public health planners to enhance health risk communication preparedness for vulnerable populations has been described in detail after the influenza epidemic in 2008. ${ }^{13}$ Despite the theoretical preparedness, we are still mired in a COVID-19 infodemic today. This emphasises the need for communicating risk information as a filler for the gap between what experts think people should know and what the wider population really want to know. ${ }^{12}$

Misinformation can lead to irreversible damage in many ways. This necessitates the design, production and dissemination of preventive measures for infodemic prophylaxis. In an agent-based model created by Branard J et al. they analysed the effect of sharing harmful advice on human risk-taking behaviour. They proposed a ratio of 60:40 of good:bad advice circulating in the population in order to negate the impact of misinformation on an outbreak. They also concluded that by reducing the sharing ability of harmful information of just $20 \%$ of the population, a reduction in disease outbreak outcomes could be achieved. ${ }^{14}$

With regards to social media, while some studies from China have linked the duration of social media exposure positively with higher risks of anxiety and depression during the COVID-19. ${ }^{15,16}$ there is also evidence of it aiding government and health agencies by drawing attention towards public emergencies and as a mode of mass communication. ${ }^{17}$

On the other hand in an analysis on misinformation on Twitter, Kouzy et al. reported that $24.8 \%$ of the 673 tweets they analysed included misinformation and $17.4 \%$ included unverifiable information regarding the COVID-19. Even though the Tweets from healthcare/public health accounts had the lowest rate of unverifiable information, it was a substantial fraction $(12.3 \%)$ of their Tweets. ${ }^{18}$

\section{Herd Immunity for an Infodemic}

Herd immunity can be defined as the resistance to the spread of a contagious disease within a population that results if a sufficiently high proportion of individuals are immune to the disease, especially through vaccination. The mechanism through which herd immunity protects the population is explained in Figure 3. A proportion of the population, chosen randomly, that must be vaccinated to achieve herd immunity threshold, is called the critical vaccination level $\left(\mathrm{V}_{\mathrm{c}}\right)$

$\mathrm{V}_{\mathrm{c}}$ in turn depends on the basic reproduction number $\mathrm{R}_{0}$ of the infection. $\mathrm{R}_{0}^{\mathrm{c}}$ is defined as the expected number of secondary cases produced by a single infection in a completely susceptible population. The relationship between $\mathrm{V}_{\mathrm{c}}$ and $\mathrm{R}_{0}$ :

$$
\mathrm{V}_{\mathrm{c}}=1-1 / \mathrm{R}_{0}
$$

For example, if the $\mathrm{R}_{0}$ for an infection is 4 , for herd immunity to develop for the infection its $V_{c}$ will be:

$$
\mathrm{V}_{\mathrm{c}}=1-1 / \mathrm{R}_{0}=1-1 / 4=3 / 4
$$

This implies that $75 \%$ of the population needs to be immune to the infection for an $\mathrm{R}_{0}$ of 4 in order for herd immunity to be effective. As is clear from equation (1), an increase in the $\mathrm{R}_{0}$ of an infection demands a higher $\mathrm{V}_{\mathrm{c}}$.

We can apply this formula to an infodemic, where:

Misinformant $=$ Any individual who spreads false information during an infodemic

$\mathrm{R}_{0 . \text { infodemic }}=$ The expected number of secondary misinformants produced by a single

misinformant in a completely susceptible population

$\mathrm{V}_{\text {c.infodemic }}=1-1 / \mathrm{R}_{0 \text {.infodemic }}$

$=$ The proportion of the population that must be immunised

against

Misinformation for herd immunity against an infodemic to be achieved.

The availability of connectivity today can lead to a high value of $\mathrm{R}_{0 \text {.infodemic' }}$ in turn increasing the $\mathrm{V}_{\text {c.infodemic }}$ closer to $100 \%$. This would mean reaching out to practically every individual in order to immunise him/her against misinformation - a task that is practically impossible on a one-on-one basis. Following are some ways that can enable herd immunity for an infodemic, driven primarily by easy use of currently available technology (Figure 4).

(i) Reduce $R_{0 \text {.infodemic }}$ : A reduction of $R_{0 \text {.infodemic }}$ results in a lower $V_{\text {c.infodemic }}$. Since $\mathrm{R}_{0 \text {.infodemic }}$ can be controlled unlike that of an infection, this is a possibility. An example of this was the reduction in the number of permissible forwards by WhatsApp in early April 2020 to reduce the spread of fake COVID-19 related information.

(ii) An information vaccination programme: A swift production and wide dissemination of information with a top-down approach, by an international group that is perceived, by a large part of the population, to be seen to be unbiased. This information must be (a) prepared with many supporting scientific advisors (b) from across the breadth of the population, (c) should be translated into as many mainstream and local languages as possible and (d) disseminated as widely as possible (e) as swiftly as possible and (f) coordinated in time as well as content. This will ensure that all members of the population receive the appropriate dose of the 'information vaccine shot', thus reducing the risk of a 'strain of incorrect information' released by others reaching the population. We call this "an information vaccination programme".

(iii) Modified Herd immunity: Identify immune 'influencers' in the population who disseminate facts, gradually immunising the susceptible population and converting the misinformants to influencers. For this model to function successfully, identification of individuals that are trustworthy within a community and who understand local beliefs and traditions is crucial. (Figure 3)

\section{CONFLICT OF INTEREST}

The authors declare none.

1 Just as numbers related to the economy e.g. unemployment, inflation, GDP are published in a coordinated fashion, the population could have faith in a single information dissemination body. 


\section{ABBREVIATIONS}

COVID-19: Coronavirus disease 2019; WHO: World Health Organization; CFR: Case Fatality Rate; ME-CFR: Mid-Epidemic Case Fatality Rate; Vc: Critical vaccination level; $\mathbf{R}_{\mathbf{0}}$ : Reproduction number,

$\mathbf{R}_{\mathbf{0 . \text { infodemic }}}$ : Reproduction number of an infodemic; $\mathbf{V c}_{\text {. }_{\text {infodemic }}}$ : Critical vaccination level of an infodemic; GDP: Gross Domestic Product.

\section{REFERENCES}

1. Novel Coronavirus (2019-nCoV) Situation Report 13. World Health Organization. 2020. [cited 2020 Feb 2]Available from: https://www.who.int/docs/ default-source/coronaviruse/situation-reports/20200202-sitrep-13-ncov-v3. pdf?sfvrsn=195f4010_6

2. WHO Director-General's opening remarks at the media briefing on COVID-19 - 3 March 2020. World Health Organization. 2020. [cited 2020 Mar 3]Available from: https://www.who.int/dg/speeches/detail/who-director-general-s-openingremarks-at-the-media-briefing-on-covid-19--3-march-2020

3. Edition.cnn.com. Coronavirus death rate is lower than previously reported - but it's still deadlier than flu, study says. 2020. [updated 2020 Mar 30; cited 2020 Mar 30]. Available from: https://edition.cnn.com/world/live-news/coronavirusoutbreak-03-30-20-intl-hnk/h_0fec101fbe30a36886e73a96920bbd38

4. Economictimes.indiatimes.com. How high is the kill rate of coronavirus? Here's what a new study found. 2020. [updated 2020 Apr 2; cited 2020 Apr 3]. Available from: https://economictimes.indiatimes.com/news/international/ world-news/how-high-is-the-kill-rate-of-covid-19-heres-what-a-new-studyfound/articleshow/74925141.cms?utm_source=contentofinterest\&utm medium=text\&utm_campaign =cppst

5. Economictimes.indiatimes.com. India's COVID-19 death rate lower than many developed nations like US, UK: Medical experts. 2020. [updated 2020 Apr 10 cited $2020 \mathrm{Apr} 10$ ]. Available from: https://economictimes.indiatimes.com/news/ politics-and-nation/indias-covid-19-death-rate-lower-than-many-developednations-like-us-uk-medical-experts/articleshow/75084199.cms?utm source $=$ contentofinterest\&utm_medium $=$ text\&utm_campaign $=$ cppst

6. Livemint.com India COVID-19 death rate lower than many developed nations, say experts. 2020. [updated $2020 \mathrm{Apr} 10$; cited $2020 \mathrm{Apr} 10$ ] Available from: https://www.livemint.com/news/india/india-covid-19-death-rate-lower-thanmany-developed-nations-say-experts-11586524055038.html

7. Timesofindia.indiatimes.com.Maharashtra Covid-19 mortality rate one of the highest in the world. 2020. [updated 2020 Apr 16; cited 2020 Apr 16] Available from: http://timesofindia.indiatimes.com/articleshow/75143435.cms?utm_ source $=$ contentofinterest\&utm_medium $=$ text\&utm_campaign $=$ cppst

8. Ghani AC, Donnelly CA, Cox DR, Griffin JT, Fraser C, Lam TH, et al. Methods for Estimating the Case Fatality Ratio for a Novel, Emerging Infectious Disease. American Journal of Epidemiology. 2005;162(5):479-86.

9. Nath P, Patel S. Mid-Epidemic Case Fatality Rate - The Case of COVID-19: Reducing the Impact of Wrong Risk Perception. 2020. Available from: http:// dx.doi.org/10.2139/ssrn.3587402

10. Worldometers.info. COVID-19 Coronavirus / Death Rate. 2020. [updated 2020 Apr 18; cited 2020 Apr 18] Available from: https://www.worldometers.info/ coronavirus/coronavirus-death-rate/

11. Hernández-García I, Giménez-Júlvez T. Assessment of Health Information About COVID-19 Prevention on the Internet: Infodemiological Study. J MIR Public Health Surveill. 2020;6(2):e18717.

12. Vaezi A, Javanmard SH. Infodemic and Risk Communication in the Era of CoV19. Adv Biomed Res. 2020;9(1):10.

13. Vaughan E, Tinker T. Effective health risk communication about pandemic influenza for vulnerable populations. Am J Public Health. 2009;99 (Suppl 2):S324-32

14. Brainard J, Hunter PR. Misinformation making a disease outbreak worse: outcomes compared for influenza, monkeypox and norovirus. Simulation. 2020;96(4):365-74.

15. Gao J, Zheng P, Jia Y, et al. Mental health problems and social media exposure during COVID-19 outbreak. PLoS One. 2020;15(4):e0231924.

16. Ni MY, Yang L, Leung CM, et al. Mental health, risk factors and social media use during the COVID-19 epidemic and cordon sanitaria among the community and health professionals in Wuhan, China. JMIR Public Health Surveill. 2020;10:2196/19009.

17. Zhao $Y$, Cheng $S, Y u X, X u ~ H$. Chinese Public's Attention to the COVID-19 Epidemic on Social Media: Observational Descriptive Study. J Med Internet Res. 2020;22(5):e18825.

18. Kouzy R, Abi JJ, Kraitem A, et al. Coronavirus Goes Viral: Quantifying the COVID-19 Misinformation Epidemic on Twitter. Cureus. 2020;12(3):e7255.

Cite this article: Patel SD, Nath P. Infodemic within a Pandemic - The Case of COVID-19 and Urban India. Int J Med Public Health. 2020;10(3):114-8. 